\title{
Teenage sexuality: implications for controlling AIDS
}

\author{
H CURTIS, C LAWRENCE, ${ }^{*}$ AND J TRIPP \\ Department of Child Health, Postgraduate Medical School and ${ }^{*}$ Department of Mathematical Statistics and \\ Operational Research, University of Exeter
}

SUMMARY A study on 761 teenagers aged 15-17 years showed that $56 \%$ of both sexes had had a steady or serious relationship. For about $40 \%$ of both sexes intercourse was a part of this relationship. Teenagers know how AIDS is transmitted, but only one third indicated personal concern about the epidemic. Only a fifth anticipate a single monogamous relationship. Significantly more girls than boys are planning to have fewer partners. Of these not anticipating monogamy three quarters mentioned the use of condoms. If education is to be effective in reducing the AIDS epidemic it must be sufficiently relevant to create and maintain changes in life style and must also educate teenagers before they have established patterns of behaviour.

A major way in which the impact of the AIDS epidemic could be reduced is by public education and individual risk reduction. If education is to be effective it must begin in the teenage years before patterns of sexual behaviour have been established. There are few published data on the effect of the government AIDS campaign on the teenage population who are potentially the generation most at risk from the epidemic.

This study was undertaken as an extension of our previous study of teenage pregnancy in east Devon. ${ }^{1}$ Between March and October 1987 we surveyed teenagers aged between 15 and 17 years, from seven schools in a semirural area, to determine how they viewed the development of teenage relationships, to establish the extent of sexual experience, and to assess their knowledge of AIDS.

\section{Subjects and methods}

The seven schools were selected to ensure adequate size groups for statistical analysis of city and rural populations, of the intellectually able, and of social class I and II. They included three coeducational comprehensives, two single sex private schools, a sixth form college, and the last grammar school year (lower sixth) of a school recently made comprehensive; all were approached via the headmaster or principal, in the first instance by letter and then by a visit to explain the nature of the research. Consent was obtained from the parents of the fourth and fifth formers. The study was approved by the district research ethics committee.
The teenagers were seen either in class or year groups. The same format was used each time a school was visited. A doctor, introduced by a teacher, spoke for 5-10 minutes about the study and its aim to find out about the development of relationships, making clear we were aware that $\equiv$ some teenagers would be sexually active. Emphasis was placed on the complete confidentiality of the questionnaire, the necessity for serious consideration of the questions, and accuracy for the sake of the research. The need for us to have a record of their own view rather than what they expected we would like or they 'should' say was stressed.

All members of the year groups selected by the researchers were present for the introduction; in no case was parental consent withheld. The teenagers were encouraged to create their own personal space in which to answer. They were told that they need not complete it if they did not wish to. Seven hundred and sixty one questionnaires were completed; four were returned blank or incomplete and these were take to represent refusals. One hundred and forty two $(19 \%)$ of the teenagers who had completed the questionnaire were asked to discuss their questionnaire confidentially with one of the researchers; one refused. This check allowed verification that the questions had been understood correctly.

We were able to determine from the questionnaire whether any individual was sexually experienced using data on their most serious relationship, their knowledge of the 'normal' progression for their friends at each stage of a relationship, and whether 
the teenager agreed with that progression for themselves. The sexual activity of each teenager whose questionnaire was verified was checked verbally and compared with the data derived from the questionnaire. A number of teenagers did not answer all the questions.

\section{Results}

Fifty six per cent of both sexes (175/311 boys and $212 / 374$ girls) had had a relationship that they regarded as steady or more serious, a quarter a less serious friendship, and just under a fifth had never had a girl or boyfriend (50/311 boys and 53/374 girls).

The perception of their friends' relationships was used to explore the development of teenage relationships and the prevalence of full sexual activity. The figure shows how the girls expected a relationship among their friends to progress with a fifth expecting no physical involvement on their first date, although most expected to be kissing. By the fourth date virtually all expected kissing and a third petting. By the time the relationship was regarded as steady half expected their friends to be having intercourse and over $90 \%$ to be having intercourse when the relationship was serious.

The pattern for the boys was not significantly different and again half expected their friends to be having intercourse when the relationship was steady.
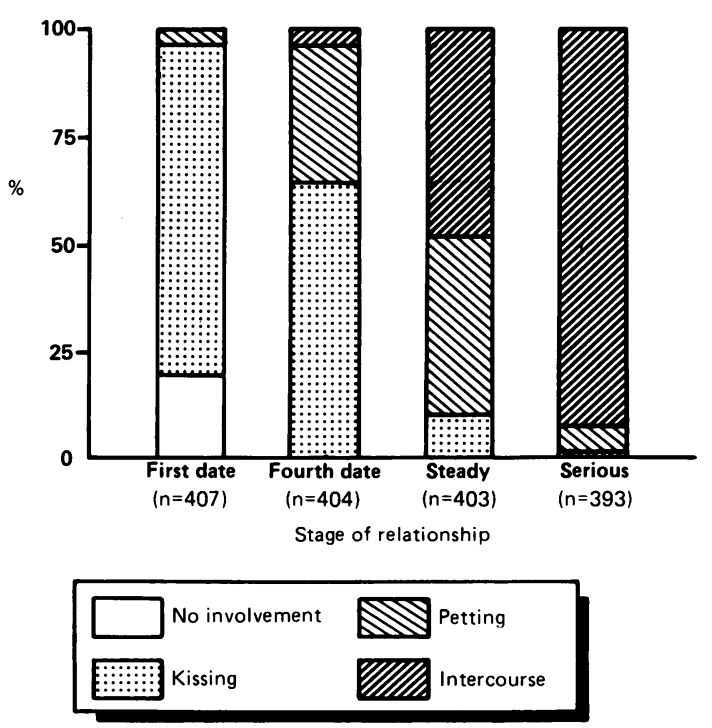

Figure Expected progression of relationship among female friends.
It was important to define what the teenagers meant by 'steady'. Over half of the boys and just under half of the girls said that a steady relationship would be established within two months of going out with the same person. Less than a tenth gave a time of greater than six months. The median time was eight weeks for boys and 10 weeks for girls (table 1 ).

Using the derived estimate of sexual intercourse a fifth of the total population of 15 year olds were sexually experienced as were a quarter of 16 and 17 year olds (table 2 ). When only those who have had a steady or serious relationship are considered, this figure is almost doubled for girls at all ages, and for the boys the numbers increased from a third at 15 years to about half at 17 years.

A variation in the number who were fully sexually active was noted between schools with $34 \%$ of fifth form girls and $21 \%$ of fifth form boys at one coeducational comprehensive school being experienced in contrast with $18 \%$ and $14 \%$ respectively at another coeducational comprehensive school (table 3).

A grouping effect was noted between friends with significantly more of those who were sexually active

Table 1 Teenagers' definition of a steady relationship

\begin{tabular}{|c|c|c|}
\hline \multirow{2}{*}{$\begin{array}{l}\text { Minimum period of } \\
\text { relationship (months) }\end{array}$} & No (\%) girls & No $(\%)$ boys \\
\hline & $(n=324)$ & $(n=258)$ \\
\hline $1-2$ & $138(43)$ & $150(58)^{*}$ \\
\hline $3-4$ & 113 (35) & $69(27)$ \\
\hline $5-6$ & 44 (14) & $22(9)$ \\
\hline$>6$ & $29(9)$ & 17 (7) \\
\hline Median (weeks) & 10 & 8 \\
\hline
\end{tabular}

*Significant difference $(\mathrm{p}<0 \cdot 001)$.

Table 2 No (\%) of teenagers who have had intercourse

\begin{tabular}{llll}
\hline & \multicolumn{1}{l}{ Age (years) } & \\
\cline { 2 - 4 } & 15 & 16 & 17 \\
\hline $\begin{array}{l}\text { Girls: } \\
\text { From the whole } \\
\text { group } \\
\text { Of those with a } \\
\text { steady or serious } \\
\text { relationship }\end{array}$ & $40 / 208(19)$ & $38 / 152(25)$ & $13 / 57(23)$ \\
$\begin{array}{l}\text { Boys: } \\
\text { From the whole } \\
\text { group } \\
\text { Of those with a } \\
\text { steady or serious } \\
\text { relationship }\end{array}$ & $25 / 100(40)$ & $37 / 79(47)$ & $13 / 32(41)$ \\
\hline
\end{tabular}


having friends who were also experienced; this was true for both sexes.

The teenagers were asked to indicate how many of their friends said they were sexually experienced and how many they thought were experienced. The results from both questions were similar, table 4 showing what friends 'said'. The boys' estimates of the numbers of either their male or female friends who were sexually active and the girls' estimates of their female friends activity broadly corresponded to the estimate of sexual activity derived from the data (table 2), but girls gave significantly higher estimates of the number of male friends who they thought were or said they were having intercourse. There was a trend for more of the older teenagers of either sex to be sexually experienced. The increase of sexual experience with age was related to the number who had had a steady or more serious relationship with the amount of sexual activity within such relationships being similar at 15 and 17 years for girls and increasing from a third to a half for the boys.

There was no significant difference by age and

Table 3 Variation in sexual activity between teenagers at different schools

\begin{tabular}{lcc}
\hline School and year group & No $(\%)$ girls & No (\%) boys \\
\hline $\begin{array}{l}\text { Fourth form (age 15): } \\
\text { Private }\end{array}$ & $4 / 39(10)$ & \\
& & \\
Fifth form (age 16): & $24 / 70(34)$ & $13 / 61(21)$ \\
Comprehensive 1 & $13 / 47(28)$ & $11 / 50(22)$ \\
Comprehensive 2 & $16 / 88(18)$ & $14 / 100(14)$ \\
Comprehensive 3 & $9 / 65(14)$ & \\
Private & & \\
Sixth form (age 17): & $8 / 43(19)$ & $4 / 32(13)$ \\
Comprehensive 3 & $4 / 11(36)$ & $14 / 59(24)$ \\
Private & $1 / 9(11)$ & $8 / 21(38)$ \\
Grammar & $12 / 45(27)$ & $6 / 21(29)$ \\
College & & \\
\hline
\end{tabular}

Table 4 Perception of friends' sexual activity by both those who are and are not sexually active themselves

\begin{tabular}{lll}
\hline & No (\%) girls & No (\%) boys \\
\hline $\begin{array}{l}\text { At least half male } \\
\text { friends experienced: }\end{array}$ & $70 / 218(32)$ & $28 / 206(13)$ \\
$\quad \begin{array}{l}\text { Virgins } \\
\text { Sexually active }\end{array}$ & $54 / 74(73)$ & $23 / 57 \quad(40)$ \\
At least half female & & \\
$\quad$ friends experienced: & $54 / 282(19)$ & $35 / 152(23)$ \\
$\quad$ Virgins & $44 / 75(59)$ & $30 / 56 \quad(54)$ \\
\hline
\end{tabular}

sexual activity and career plans for either sex except that for the 15 year old girls where significantly more of those who were planning to go on to higher education were virgins $(p<0.05)$.

The sexually experienced girls were more likely to have started their periods before 12 years of age than those who were still virgins $(p<0.001)(35 / 85$ compared with 37/301).

The boys had less supervision by parents than the girls. There was no difference in parental supervision for the boys who were sexually experienced except that more parents of boys who were virgins stayed awake until they were home $(p<0 \cdot 05)$. In contrast the girls who were sexually experienced had significantly less supervision in terms of permission to go out, time to be home by, parents staying awake, and parents knowing where their daughters were $(p<0.01)$. For the boys there was no significant difference between sexual activity and the social class of the family (using the Registrar General's classification of father's occupation) (table 5), but the girls from the non-manual sector (I-IIIn) were significantly less likely to be sexually active than those from social class IIIm-V.

The teenagers were asked to state in their own words what they thought AIDS was (table 6). Significantly more of the 17 year olds (that is, sixth formers) wrote down what the initials stood for and that it affected the immune system. However, significantly more of the 15 year olds than the 17 year olds stated it was sexually transmitted. A quarter at all ages wrote down that there was no cure.

Significantly more of the girls than the boys were personally worried about AIDS but only $36 \%$ of girls and $30 \%$ of the boys felt that AIDS might affect them personally and were therefore concerned about it as a risk. The teenagers were asked to state what precautions they would take against contracting AIDS. A fifth of girls and less than a fifth of boys planned to have a single monogamous relationship (table 7). Of those who did not state this $75 \%$ of the girls and just under $70 \%$ of the boys mentioned the use of condoms. Significantly more girls than boys said they would want to know their partner well

Table 5 Sexual activity and social class

\begin{tabular}{lcc}
\hline & No $(\%)$ girls & No (\%) boys \\
\hline Class: & & \\
I-II & $31 / 190(16)$ & $29 / 150(19)$ \\
III non-manual & $7 / 47(15)$ & $13 / 39(33)$ \\
III manual & $29 / 87(33)$ & $13 / 59(22)$ \\
IV-V & $8 / 18(44)$ & $3 / 21(14)$ \\
\hline
\end{tabular}


Table 6 Replies to the question (by age group)-What is AIDS?

\begin{tabular}{|c|c|c|c|c|c|c|}
\hline & \multicolumn{3}{|l|}{ Girls } & \multicolumn{3}{|l|}{ Boys } \\
\hline & $\begin{array}{l}\leqslant 15 \\
(n=189)\end{array}$ & $\begin{array}{l}16 \\
(n=148)\end{array}$ & $\begin{array}{l}\geqslant 17 \\
(n=55)\end{array}$ & $\begin{array}{l}\leqslant 15 \\
(n=132)\end{array}$ & $\begin{array}{l}16 \\
(n=82)\end{array}$ & $\begin{array}{l}\geqslant 17 \\
(n=82)\end{array}$ \\
\hline \multicolumn{7}{|l|}{$\%$ Who stated that it was: } \\
\hline Acquired immune deficiency syndrome & 16 & 31 & 40 & 23 & 33 & 54 \\
\hline Virus & 15 & 19 & 18 & 10 & 11 & 24 \\
\hline Sexually transmitted disease & 61 & 40 & 40 & 56 & 38 & 29 \\
\hline Associated with drugs/needles & 7 & 7 & 13 & 9 & 5 & 1 \\
\hline Affected immune system & 22 & 39 & 44 & 26 & 37 & 59 \\
\hline Associated with secondary infection & 12 & 14 & 9 & 7 & 11 & 28 \\
\hline Associated with homosexuals & 4 & 5 & 5 & 5 & 4 & 2 \\
\hline Incurable & 27 & 26 & 20 & 22 & 24 & 23 \\
\hline
\end{tabular}

Table 7 Precautions the teenagers would take against AIDS

\begin{tabular}{|c|c|c|}
\hline & No (\%) girls & No (\%) boys \\
\hline $\begin{array}{l}\text { All teenagers: } \\
\text { Would not use drugs/ } \\
\text { care with needles } \\
\text { Monogamous relationships }\end{array}$ & $\begin{array}{ll}(n=417) \\
89 & 21 \\
87 & 21\end{array}$ & $\begin{array}{ll}(n=344) \\
55 & 17 \\
56 & 16\end{array}$ \\
\hline $\begin{array}{l}\text { Of those who did not state a } \\
\text { Would use condoms } \\
\text { Would have fewer } \\
\text { partners/know partner well }\end{array}$ & $\begin{array}{l}\text { onogamous rel } \\
(n=330) \\
24073 \\
17954\end{array}$ & $\begin{array}{l}\text { tionship: } \\
(\mathrm{n}=287) \\
19969 \\
9433^{*}\end{array}$ \\
\hline
\end{tabular}

*Significant difference girls $v$ boys $(\mathrm{p}<0.001)$.

before having intercourse and planned to have fewer partners.

\section{Discussion}

Farrell in her study in the mid 70 s wrote about intercourse being part of a stable teenage relationship, although no specific definition of 'stable' was made. ${ }^{2}$ Over three quarters of our population defined a steady relationship as going out with the same person for a certain number of weeks-the median being 10 weeks for girls and eight weeks for boys. For just under a half of the girls and between a third and a half of the boys this type of relationship was associated with intercourse and in the age range 15-17 years the existence of a serious relationship was a much stronger determinant of sexual activity than age. Most teenagers included within the framework of this definition a degree of exclusiveness and faithfulness.

The girls who started their periods early were more likely to be sexually active as has been previously reported in pregnant teenagers ${ }^{13}$; a possible explanation being that they are physically mature and engage in serious relationships at an earlier age but do not have the corresponding emotional maturity to realise the implications of sexual activity and possible pregnancy. The experienced girls were also subject to less supervision by their parents, thus providing them with more opportunities for intercourse as has been previously reported in the teenage pregnancy study. ${ }^{1}$ Factors that differentiate virgin and experienced boys are not so clearly demonstrated.

Selection of schools in this study was made to give a cross section of school types and to ensure adequate representation of each social class group. The largest group of parents were from social class II and the majority were from the non-manual sector (I-IIIn) using the Registrar General's classification of father's occupation. This is explained by the rural area from which many pupils were drawn and by the fact that $25 \%$ of the study population were drawn from private schools. Significantly more girls who were experienced came from the lower social classes, but boys who were experienced came from all home backgrounds. There was no difference in terms of future plans and sexual activity except with the youngest girls.

The different rates of sexual activity between the comprehensive schools cannot be accounted for by a difference in social class distribution. The school itself appeared to have an effect on activity. It was difficult to assess whether this was related to the teenagers themselves, or to the environment and atmosphere of the school or to the curriculum, or a combination of these factors. The city school where the classrooms were locked between lessons, where there were few pictures on the wall, where children ate their lunch in the cloakroom, and where there appeared to be a large number of supply teachers, had a higher rate of sexual intercourse than either of the rural comprehensives that had a similar social class structure. Rates were not significantly different 
in the private schools, which had a much higher percentage of high social class families.

Most teenagers remembered teaching on the biological facts of reproduction, contraception, and sexually transmitted diseases and in a previously reported study there were requests for more nonbiological teaching on relationships, pressures, etc. The efficacy of the teaching did appear to be related to the enthusiasm and commitment of the staff and the respect the teenagers had for the teachers. ${ }^{4}$

Sexual activity among teenagers is therefore not restricted to the non-academic from the lower socioeconomic groups but is regarded as a normal part of a relationship for teenagers of all abilities and background.

Previous studies noted a sex discrepancy in the number of teenagers who were sexually experienced in their mid teens. ${ }^{2} 5$ Farrell, writing in the 1970 s, suggested that $55 \%$ of males and $46 \%$ of females between 16 and 19 years had experienced intercourse. Examination of Farrell's data shows that $12 \%$ of all girls and $31 \%$ of all the boys said they first had intercourse before 16 years. In this study the numbers were very similar, and although the difference was not significant more girls were sexually active than boys at 15 years. This perhaps is what one would expect considering that girls mature physically earlier than boys and tend to go out with boys older than themselves. The number who are sexually active at 16 and 17 years is probably an underestimate because the sample did not include 16 and 17 year olds who had left school and might be expected to be more sexually active.

Experienced girls and boys were significantly more likely to have friends who were also perceived as being sexually active. Peer influence is a powerful pressure to conform to what is regarded as 'normal' behaviour. ${ }^{6}$ The perception by girls that the boys are more active than they actually are was clearly seen in the overestimation of sexual activity of male friends. Although $40 \%$ of the teenagers involved in a steady or more serious relationship were sexually experienced only a quarter of the total teenage population studied were experienced. Most teenagers under 18 years are therefore not experienced and one ploy in education could be to attempt some reduction of this peer pressure and to encourage the normality of relationships without intercourse.

The effect of media on behaviour is difficult to quantify. Bury has stated that 'In relation to sexual matters there seems little doubt that television, films, pop culture and advertising have all affected behaviour by emphasising the glamour of sex ... for some years now, and long before it was the case, the media has given the impression that most teenagers are sexually experienced'. ${ }^{3}$
If teenagers are sexually active in their mid teens it is common for them to have a series of exclusive sexual relationships before marriage, ${ }^{4}$ which has been called serial monogamy. ${ }^{37}$ Serial monogamy exposes each partner to their partners previous partners with the associated medical risks of sexually transmitted diseases and cervical cancer. Sexually transmitted diseases lead to the secondary problems of infertility and the risk of ectopic pregnancy in the girls; HIV infection leads to the major problem of acquired immune deficiency syndrome in both men and women.

The teenagers had a good understanding of how AIDS is transmitted and were reasonably knowledgeable as to what AIDS is. For most it was not seen as a problem that would personally affect them.

Although they knew AIDS was transmitted by sharing needles in drug abuse very few mentioned this aspect in describing what AIDS was and similarly few mentioned not being involved in the drug scene. This can probably be explained by that fact that for the majority drug abuse was not personally relevant to them.

Only a fifth of the teenagers anticipated having a single monogamous relationship. Of those who did not plan monogamy about three quarters mentioned using condoms. Contraceptive usage among young people is, however, haphazard, ${ }^{8}$ often because intercourse is unplanned, ${ }^{9}$ and the sheath has never? been regarded as a reliable form of contraceptive in this age group. ${ }^{10}$

Significantly more of the girls than boys stated the importance of knowing their partner well before having intercourse and of planning to limit the number of partners they had. Previous studies have shown that boys tend to be more casual in sexual relationships, ${ }^{49}$ and despite the AIDS campaign this attitude has not apparently altered. ${ }^{5}$

If education is to be effective in reducing the AIDS epidemic it must be sufficiently relevant to create and maintain changes in behaviour. As well as focusing on those groups particularly at risk it is also important to aim education programmes at young people before they have established patterns of behaviour.

Education is the responsibility of parents, school, and society as a whole. Previous evidence suggests that where parents exercise supervision and discuss such topics openly with their children, the children are less likely to become involved in early sexual activity, ${ }^{11}$ and this study supports this especially in relation to girls. Health education programmes at school are aimed at helping children take responsibility for their own long term health. In the area of sex education it would be appropriate for there to be clear statements that early intercourse and multiple 
partners are associated with important medical risks including sexually transmitted diseases and HIV infection.

The present generation of teenagers is potentially most at risk of AIDS. There is an opportunity through education in its widest sense to reduce this risk before patterns of behaviour are established.

We warmly acknowledge the help and support of the staff and pupils at the schools; expert advice from Dr John Balding, Schools Health Education Unit, University of Exeter; financial support from the Children's Research Fund and the Northcott Devon Medical Foundation (HAC); and our ever patient secretaries Ann Hoskins and Debbie Perry.

\section{References}

${ }^{1}$ Curtis HA, Lawrence CJ, Tripp JH. Sexual intercourse and pregnancy. Arch Dis Child 1988;63:373-9.

2 Farrell C. 'My mother said . . .' London: Routledge and Keegan Paul, 1978.

${ }^{3}$ Bury J. Teenage pregnancy in Britain. London: Birth Control Trust, 1984.
${ }^{4}$ Curtis HA, Tripp JH, Lawrence C, Clarke WL. The influence of teenage relationships and sex education. Arch Dis Child 1988; 63:935-41.

5 Schofield M. Sexual behaviour of young people. London: Pelican; 1968.

${ }^{6}$ Osofsky JD, Osofsky HJ. Teenage pregnancy: psychosexual considerations. Clin Obstet Gynaecol 1978;21:1161-73.

${ }^{7}$ Sorensen RC. Adolescent sexuality in contemporary America. New York: World Publications, 1973.

8 Ryde-Blanquist E. Contraception in adolescents: a review of the literature. J Biosoc Sci 1978;suppl 5:129-58.

9 Zelnick M, Shah F. First intercourse among young americans. Fam Plann Perspect 1983;2:65-70.

${ }^{10}$ Fox LS. Adolescent male reproductive responsibility. Social Work in Education 1983;6:32-43.

1 Inazu J, Fox GL. Maternal influences on the sexual behaviour of teenage daughters. Journal of Family Issues 1980;11:81-102.

Correspondence to Dr JH Tripp, Department of Child Health, Royal Devon and Exeter Hospital (Wonford), Barrack Road, Exeter, Devon EX2 5DW.

Accepted 8 May 1989 